\title{
Pharmacologic Cholesterol Homeostasis Affects Prion Generation in a Synergistic Manner
}

\author{
Christina D. Orru ${ }^{1}$, M. Dolores Cannas ${ }^{1}$, Sarah Vascellari ${ }^{1}$, Claudia Abete $^{1}$, Antonella Mandas ${ }^{2}$, \\ Fabrizio Angius ${ }^{1}$, Pierluigi Cocco ${ }^{1}$, Paolo La Colla ${ }^{1}$, Sandra Dessi ${ }^{1}$ and Alessandra Pani*,
}

${ }^{l}$ Department of Biomedical Science \& Technology; ${ }^{2}$ Department of Internal Medicine University of Cagliari, Italy

\begin{abstract}
It is generally recognised that prion replication in the brain is associated with cholesterol changes. We now show that prion diseases are likely associated with systemic metabolic alterations that involve changes both in the content and distribution of the different pools of cellular cholesterol, free cholesterol and cholesterol esters, as well as of other cellular lipids, including phospholipids and triglycerides. The synergic anti-prion effect showed by drug combinations affecting cholesterol metabolism at different levels suggest that pharmacologic interventions restoring lipid homeostasis may represent a more successful therapeutic approach than drug treatments lowering cholesterol content per se (i.e. statins). Notably, our data also point to neutral lipid accumulation in peripheral cells as an easy-to-detect hallmark associated with disease and/or indicative of increased susceptibility to develop disease following infection.
\end{abstract}

Keywords: Prions, prion disorders, cholesterol homeostasis, cholesterol modulators, drug combinations.

\section{INTRODUCTION}

The elucidation of the cellular prion protein $\left(\operatorname{PrP}^{\mathrm{C}}\right)$ metabolism and of the mechanism(s) of its structural conversion into pathogenic isoforms $\left(\operatorname{PrP}^{\mathrm{Sc}}\right)$ remains a fundamental target for developing therapeutic and prophylactic strategies against prion diseases. Numerous studies hint at lipid rafts, i.e. membrane microdomains enriched in cholesterol and sphingolipids, as possible sites of prion conversion $[1,2]$, and many lines of evidence indicate that intracellular cholesterol changes readily affect the processing/trafficking of $\operatorname{PrP}^{\mathrm{C}}$ [3-5], suggesting that the process of PrP misfolding might be modulated by cholesterol homeostatic mechanisms. At present, however, although there are clear indications that raft composition is essential for the proper folding of nascent $\operatorname{PrP}^{\mathrm{C}}$, there are divergent findings on whether depletion of membrane cholesterol or its enrichment would favour PrP misfolding. A number of studies have shown a decrease in $\operatorname{PrP}^{\mathrm{Sc}}$ generation by lowering the cellular cholesterol content with statins [5-7], while other studies produced evidence that cholesterol depletion abolishes PrP-raft association, promotes its accumulation and increases substantially its misfolding [8,9]. The overall complexity of the mechanism(s) linking PrP metabolism to cellular cholesterol changes is even more complicated by the fact that prion infection/replication itself seems to have the potential to induce modifications in the cholesterol metabolism [10,11]. In this context, our recent findings in sheep scrapie indicated that modifications of cholesterol metabolism, rather than being limited to the brain, appear to be a systemic trait since also ex vivo dermal fibroblasts and blood lymphocytes of sheep suffering-from or susceptible-to scrapie display similar alterations [12-14].

*Address correspondence to this author at the Dept. Biomedical Science \& Technology, University of Cagliari, Italy; Tel: +39 070675 4209; Fax: +39 070675 4210; E-mail: pania@unica.it
In addition, in prion/cell systems we found that persistent infection is associated to metabolic changes involving, besides cholesterol, all major classes of intracellular lipids, and that treatments with drug combinations triggering lipid homeostasis determine a synergic inhibition of prion generation $[13,15,16]$.

\section{SYSTEMIC CHOLESTEROL ALTERATIONS IN SHEEP SCRAPIE}

Abnormal accumulation of cholesterol esters characterizes brain biopsies and ex vivo skin fibroblasts from sheep susceptible-to (ARQ/ARQ-) or suffering-from (ARQ/ARQ+) scrapie, with respect to scrapie-resistant sheep (ARR/ARR), Fig. (1).

In brains and skin fibroblasts from scrapie susceptible/infected sheep, the accumulation of cholesterol esters is accompanied by altered expression levels of enzymatic activities involved in cholesterol esterification (ACAT-1; up-regulated) and cholesterol trafficking (Cav-1; down-regulated), and by that of $\operatorname{PrP}^{\mathrm{C}}$ itself (up-regulated), Fig. (2).

\section{CHOLESTEROL ALTERATIONS IN PRION- INFECTED NEURONAL CELL LINES}

In prion-infected N2a cells, Nile red and filipin staining of intracellular lipids reveals changes both in the content and distribution of most intracellular lipids, Fig. (3). Notably, besides cholesterol esters and free cholesterol, also phospholipids and triglycerides appear up-regulated.

\section{ANTI-PRION ACTIVITY OF CHOLESTEROL MODULATORS}

Cell treatments with cholesterol/cholesterol ester modulators, alone or in combination with the cholesterolinterfering prion inhibitors chlorpromazine and quinacrine, show marked anti-prion activity, Figs. (4) and (5). 

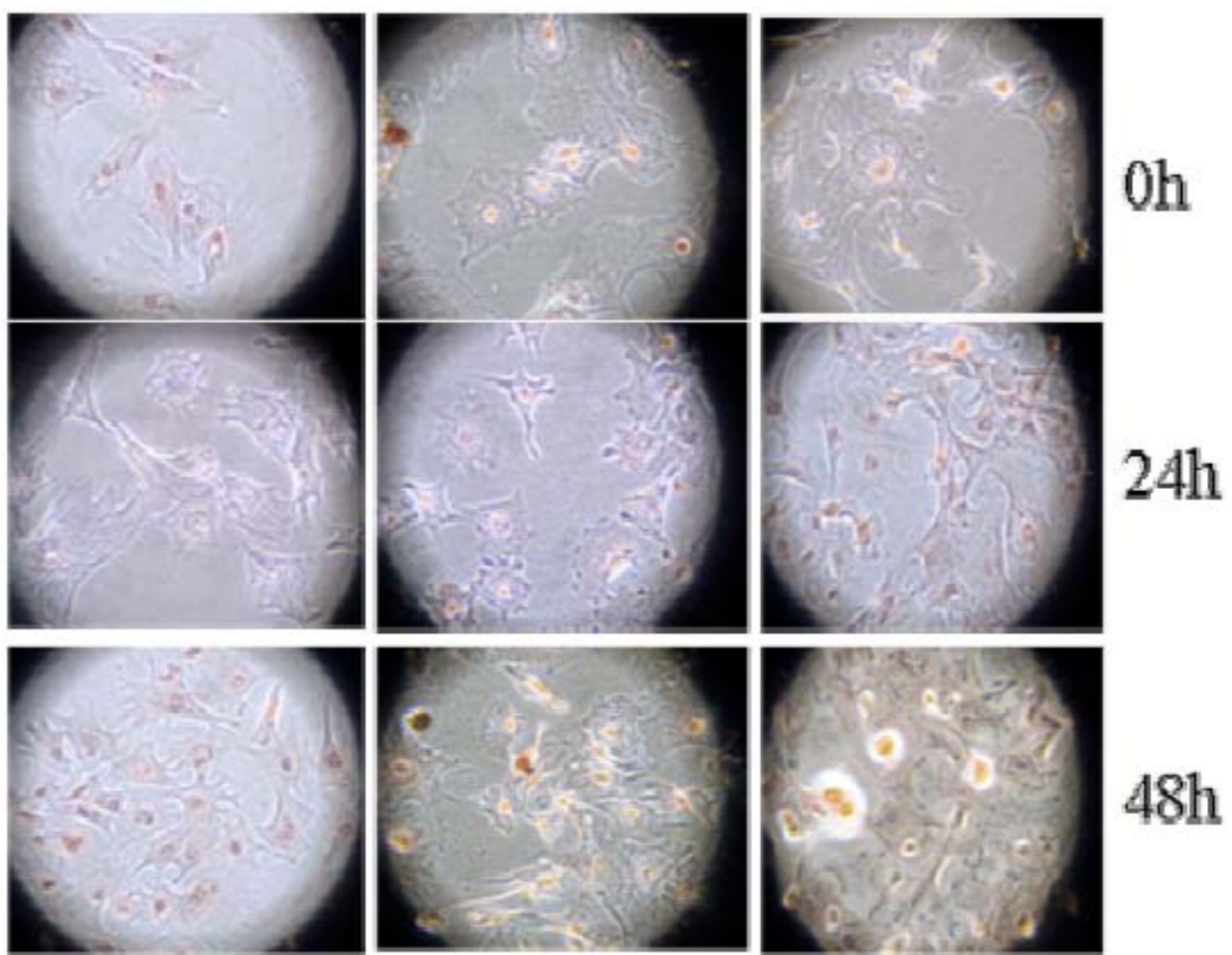

\section{$48 \mathrm{~h}$}
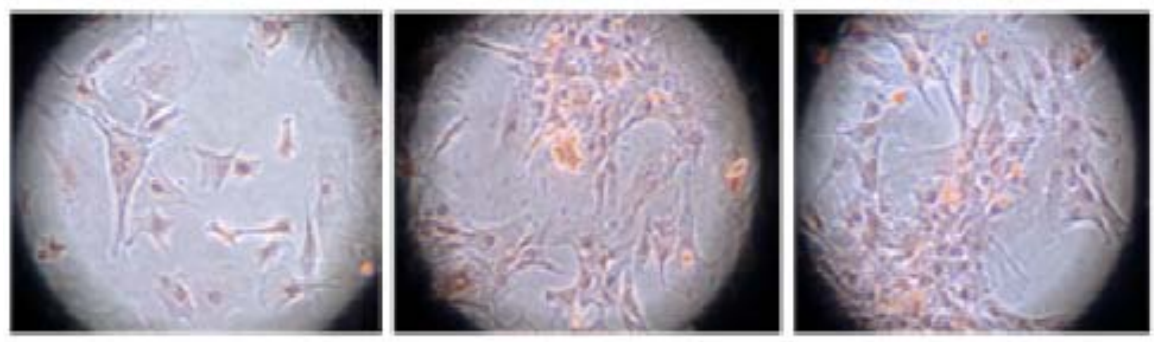

$72 \mathrm{~h}$

\section{ARR/ARR}

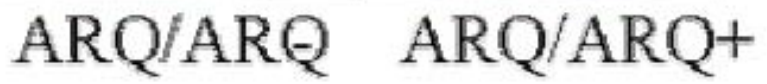

Fig. (1). Oil-red O-stained neutral lipids of cultured serum-stimulated skin fibroblasts from sheep carrying scrapie-resistant (ARR/ARR) or susceptible (ARQ/ARQ) genotypes.
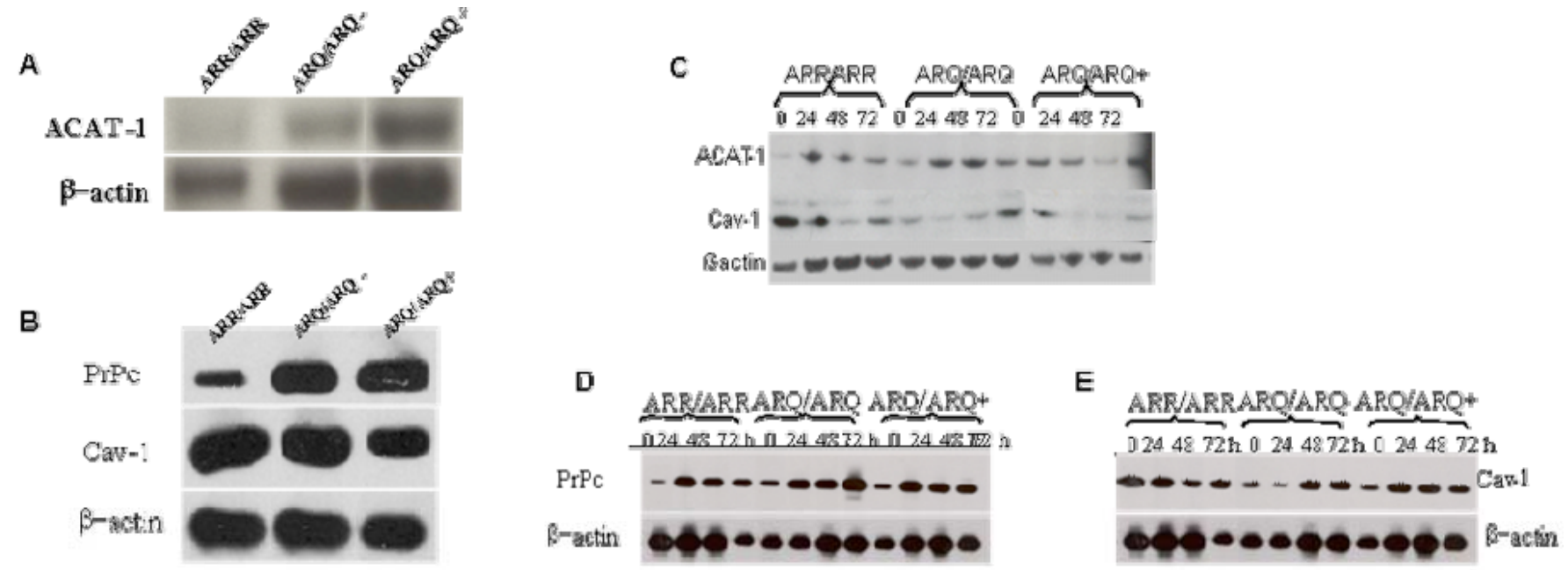

Fig. (2). ACAT-1, Cav-1 and PrP in brains (A and B) and skin fibroblasts (C-E) of sheep carrying scrapie-resistant (ARR/ARR) or susceptible (ARQ/ARQ) genotypes. 


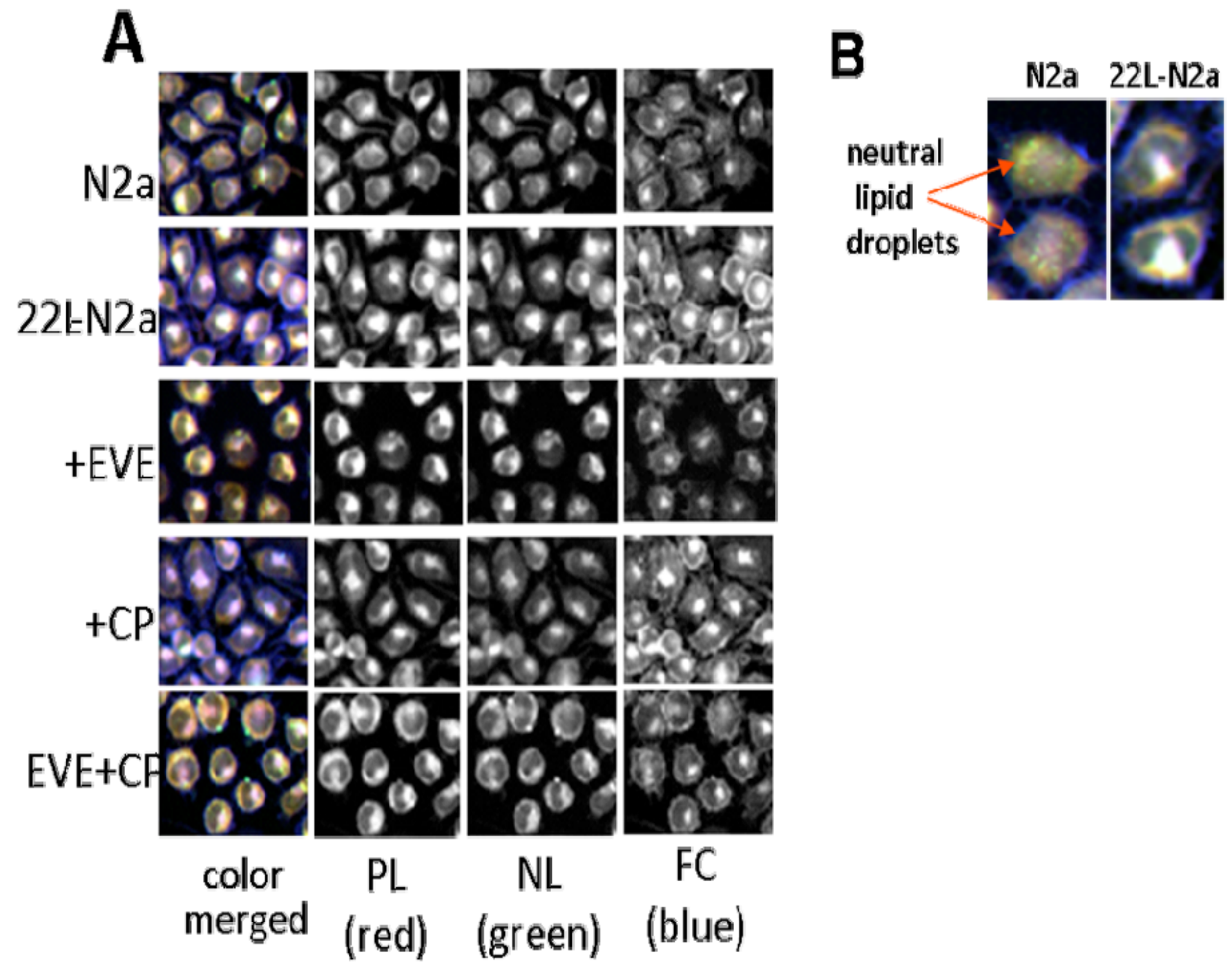

Fig. (3). Nile red and Filipin lipid staining of N2a cells.

Notably, drug combinations determine a strong synergistic anti-prion effect apparently by triggering a lipid profile similar to that of uninfected-untreated cells, see Fig. (3).

The most potent synergism is obtained with everolimus, an immunosuppressant agent that inhibits cholesterol esterification by an yet unknown mechanism, in combination with both chlorpromazine and quinacrine. Synergic interaction of the latter anti-prion drugs are also observed with pioglitazone, an anti-diabetic drug that induces redistribution of free fatty acids within the cell; verapamil, a calcium-blocking drug that inhibits cholesterol trafficking from the plasma membrane to the ER, and progesterone, a sterol hormone that affects cholesterol trafficking both from the plasma membrane and lysosomes.

As for chlorpromazine and quinacrine themselves, recent evidence, not formally excluding other reported mechanisms, indicates that these drugs might exert anti-prion effect by interfering with intracellular cholesterol: quinacrine through destabilization of cholesterol-rich membrane domains (rafts), and chlorpromazine by inducing transcriptional activation of genes involved in cholesterol biosynthesis, transport, and efflux.

\section{CHOLESTEROL HOMEOSTASIS NETWORK}

In normal condition, since membrane cholesterol appears critical for the function of raft-resident proteins, highly integrated sets of homeostatic mechanisms finely regulate free cholesterol vs. cholesterol ester pool according to the cells' need. Approximately $90 \%$ of the total cellular cholesterol resides in the membrane raft domains as free cholesterol, while only a minor amount (approximately 1$10 \%$ ) is found as cholesterol esters in cytoplasmic lipid droplets [17]. Membrane cholesterol is in a dynamic state, moving to the endoplasmic reticulum (ER) in response to changing homeostatic conditions in the cell $[18,19]$. Free cholesterol in the ER, if in excess, is converted to cholesterol esters by ACAT-1, and stored in the cytoplasm [20]. When cells need cholesterol for membrane biogenesis/function, or when cholesterol esters exceed critical threshold values, esterified cholesterol can be reconverted to free cholesterol and recycled to the membrane by cholesterol binding/transport proteins, such as Cav-1 and, for cell efflux via HDL, ABCA-1 [5,20], Fig. (6).

In pathologic condition, synthesis, esterification, and trafficking of cholesterol is deregulated leading to altered 

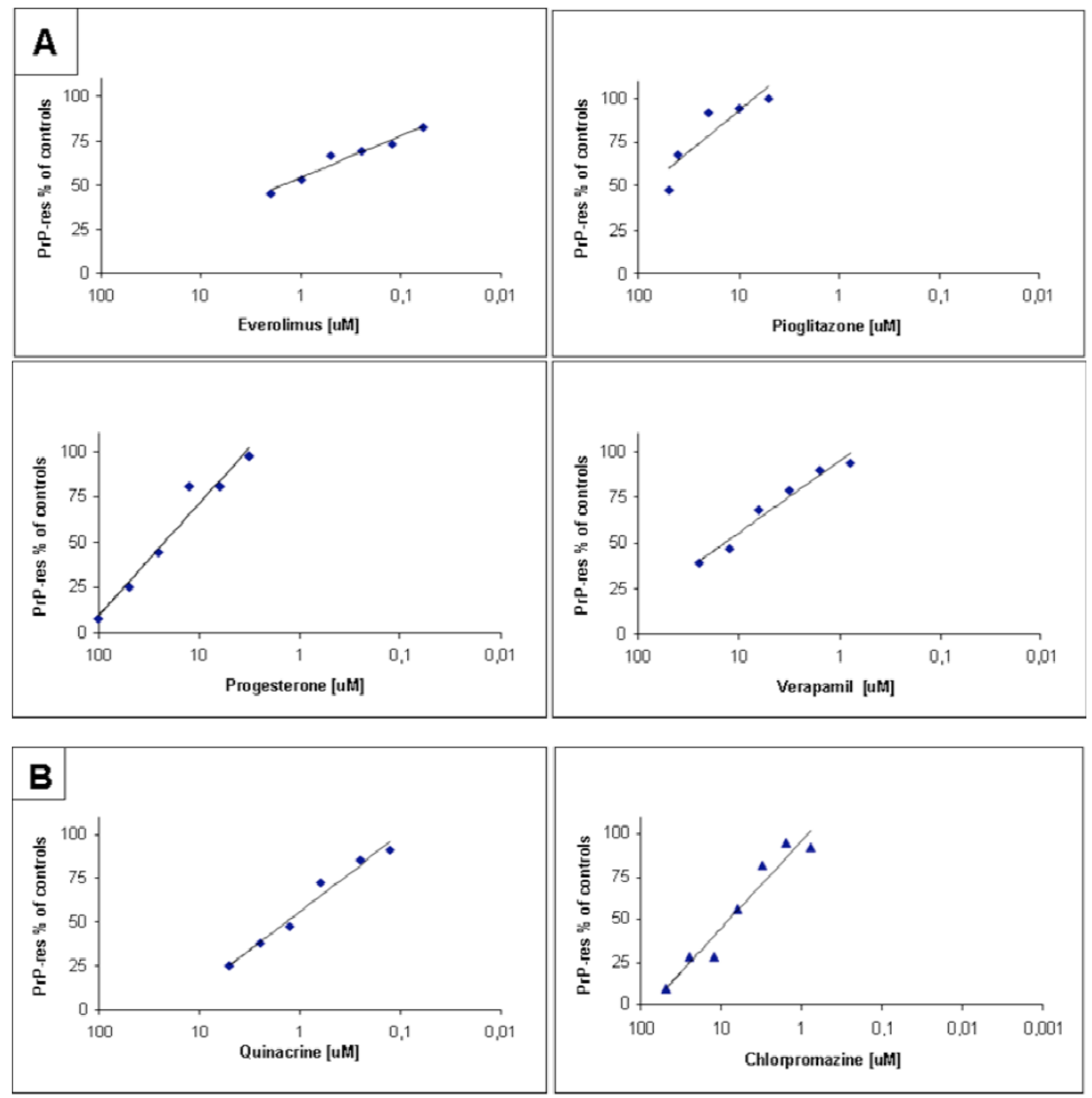

Fig. (4). Dose-response curves of anti-prion activity of cholesterol ester modulators (A) and prion inhibitors (B).

content and distribution of free cholesterol and to abnormal cytoplasmic accumulation of cholesterol esters.

The altered cholesterol homeostasis, in turn, likely affects the metabolism of other cellular lipids, such as phospholipids and tryglicerides, altogether creating in the cell a lipid environment apparently more suitable for aberrant prion protein conversion. The strong synergistic anti-prion effect of drug combinations restoring lipid homeostasis in the infected cell, supports this hypothesis.

\section{CONCLUDING REMARKS}

Altogether our results indicate that prion infection/susceptibility is associated with systemic lipid alterations and that pharmacologic cholesterol homeostasis may represent a more successful way to hamper prion generation than drug treatments lowering cholesterol content per se (i.e. statins). Overall, these data support the idea that prion infection, as well as particular cellular-PrP polymorphisms, may take advantage of preexistent and/or induced modifications of cholesterol homeostasis to create a lipid environment favorable to the initiation/progression of the aberrant processing of prion protein.

Besides the potential significance of these results in the clinic of prion disease, our data point to neutral lipid accumulation in peripheral cells as an easy-to-detect 

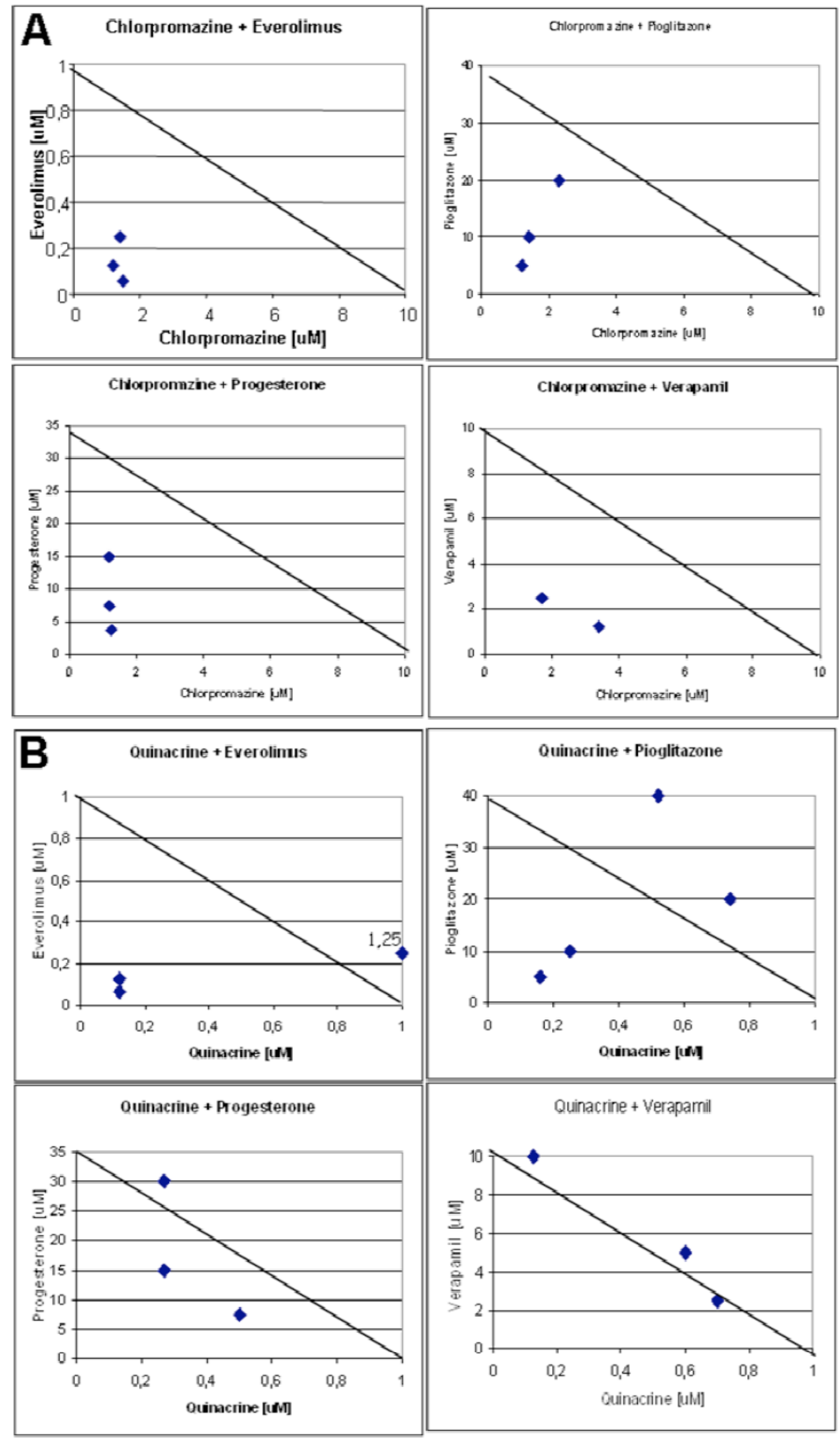

Fig. (5). Anti-prion activity of chlorpromazine (A) and quinacrine (B) in combination with the cholesterol ester modulators everolimus, pioglitazone, progesterone, and verapamil. 


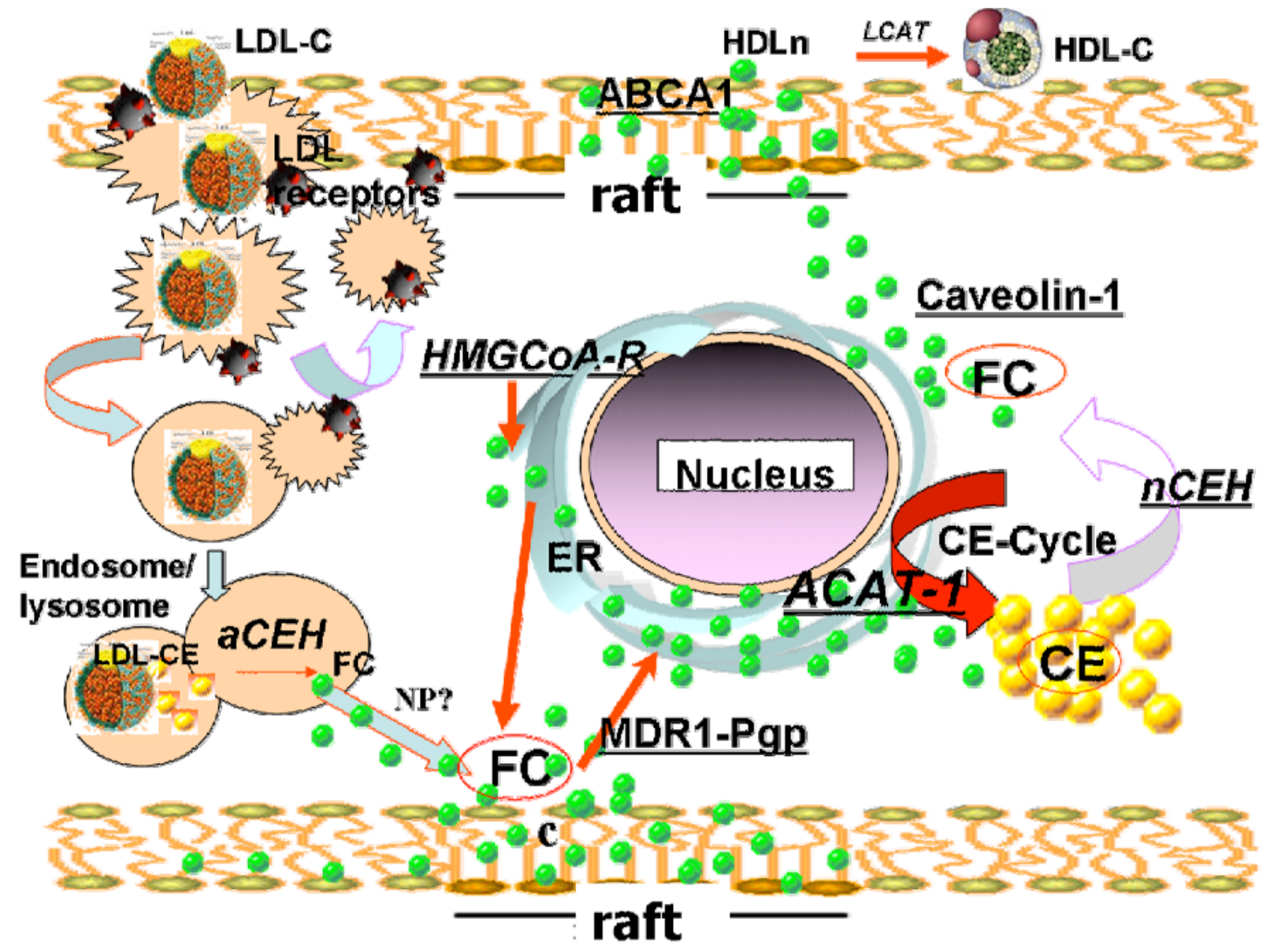

Fig. (6). Cholesterol homeostasis network.

hallmark associated with disease, and/or indicative of increased risk to develop disease following infection.

\section{REFERENCES}

[1] Simons, K.; Ehehalt R. Cholesterol, lipid rafts, and disease. J. Clin. Invest., 2002, 110, 597-603.

[2] Critchley, P.; Kazlauskaite, J.; Eason, R.; Pinheiro, T.J. Binding of prion protein to lipid membranes. Biochem. Biophys. Res. Commun., 2004, 313, 559-67.

[3] Gorodinsky, A.; Harris, D.A. Glycolipid-anchored proteins in neuroblastoma cells form detergent-resistant complexes without caveolin. J. Cell Biol., 1995, 129, 619-27.

[4] Vey, M.; Pilkuhn, S.; Wille, H.; Nixon, R.; DeArmond, S.J.; Smart, E.J.; Anderson, R.G.; Taraboulos, A.; Prusiner, S.B. Subcellular colocalization of the cellular and scrapie prion proteins in caveolaelike membranous domains. Proc. Natl. Acad. Sci. U S A, 1996, 93, 14945-49.

[5] Taraboulos, A.; Scott, M.; Semenov, A.; Avrahami, D.; Laszlo, L.; Prusiner, S.B. Cholesterol depletion and modification of $\mathrm{COOH}-$ terminal sequence of the prion protein inhibit formation of the scrapie isoform. J. Cell Biol., 1995, 129, 121-32.

[6] Gilch, S.; Kehler C.; Schätzl, H.M. The prion protein requires cholesterol for cell surface localization. Mol. Cell. Neurosci., 2006, 31, 346-53.

[7] Mok, S.W.; Thelen, K.M.; Riemer, C.; Bamme, T.; Gültner, S.; Lütjohann, D.; Baier, M. Simvastatin prolongs survival times in prion infections of the central nervous system. Biochem. Biophys. Res. Commun., 2006, 348, 697-702.

[8] Campana, V.; Sarnataro, D.; Paladino, S.; Zurzolo ,C. Detergent Resistant Domains but not the proteasome are involved in the misfolding of a PrP mutant retained in the Endoplasmic Reticulum. J. Cell Sci., 2006, 119, 433-442.

[9] Abid, K.; Soto, C. Biomedicine and diseases: Review the intriguing prion disorders. Cell. Mol. Life Sci., 2006, 63, 2342-2351.
[10] Russelakis-Carneiro, M.; Hetz, C.; Maundrell, K. Prion replication alters the distribution of synaptophysin and caveolin 1 in neuronal lipid rafts. Am. J. Pathol., 2004, 165, 1839-1848.

[11] Bach, C.; Gilch, S.; Rost, R.; Greenwood, A.D.; Horsch, M.; Hajj, G.N.; Brodesser, S.; Facius, A.; Schädler, S.; Sandhoff, K.; Beckers, J.; Leib-Mösch, C.; Schätzl. H.M.; Vorberg, I. Prioninduced activation of cholesterogenic gene expression by SREBP2 in neuronal cells. J. Biol. Chem., 2009, 284, 31260-31269.

[12] Pani, A.; Abete, C.; Norfo, C.; Mulas, C.; Putzolu, M.; Laconi, S Cannas, M.D.; Orrù, C.D.; La Colla, P.; Dessi, S. Cholesterol metabolism in brain and skin fibroblasts from sarda breed sheep with scrapie-resistant and scrapie-susceptible genotypes. Am. J. Infect. Dis., 2007, 3, 143-150.

[13] Pani, A.; Norfo, C.; Abete, C.; Mulas, C.; Putzolu, M.; Laconi, S.; Orrù, C.D.; Cannas, M.D.; Vascellari, S.; La Colla, P.; Dessì, S. Accumulation of cholesterol esters in ex vivo lymphocytes from scrapie-susceptible sheep and in scrapie-infected mouse neuroblastoma cell lines. Am. J. Infect. Dis., 2007, 3, 165-168.

[14] Orrù, C.D.; Abete, C.; Cannas, M.D.; Mulas, C.; Norfo, C.; Mandas, A.; Vascellari, S.; La Colla, P.; Dessì, S.; Pani, A. ACAT, Cav1 and PrP expression in scrapie susceptible and resistant sheep. Cent. Eur. J. Biol., 2010, 5, 31-37.

[15] Pani, A.; Norfo, C.; Abete, C.; Mulas, C.; Putzolu, M.; Laconi, S.; Orrù, C.D.; Canna, M.D.; Vascellari, S.; La Colla, P.; Dessì, S. Anti-prion activity of cholesterol esterification modulators: a comparative study in ex vivo sheep fibroblasts and lymphocytes and in mouse neuroblastoma cell lines. Antimicrob. Agents Chemother., 2007, 51, 4141-4147.

[16] Orrù, C.D.; Cannas, M.D.; Vascellari, S.; Angius, A.; Cocco, P.G.; Norfo, C.; Mandas, A.; La Colla, P.; Diaz, G.; Dessì, S.; Pani, A. In vitro synergistic anti-prion effect of cholesterol ester modulators in combination with chlorpromazine and quinacrine. Cent. Eur. J. Biol., 2010, 5, 151-165. 
[17] Schmitz, G.; Orso, E. Intracellular cholesterol and phospholipid trafficking: comparable mechanisms in macrophages and neuronal cells. Cell. Mol. Life Sci., 2001, 26,1045-1068.

[18] Maxfield, F.R.; Tabas, I. Role of cholesterol and lipid organization in disease. Nature, 2005, 438, 612-621.
[19] Simons, K.; Ikonen, E. How cell handle cholesterol. Science, 2000, 290, 1721-1726.

[20] Kurzchalia, T.V.; Parton, R.G. Membrane microdomains and caveolae. Curr. Opin. Cell Biol., 1999, 11, 424-431.

(C) Orru et al.; Licensee Bentham Open.

This is an open access article licensed under the terms of the Creative Commons Attribution Non-Commercial License (http://creativecommons.org/licenses/by-nc/3.0/) which permits unrestricted, non-commercial use, distribution and reproduction in any medium, provided the work is properly cited. 